\title{
The Performance Limitation of 10-Gbps-per- Channel-based Coarse Wavelength Division Multiplexed Passive Optical Network
}

\author{
Pimchanok Montha*, Rachata Maneekut**, and Pasu Kaewplung*** \\ Department of Electrical Engineering, Faculty of Engineering, Chulalongkorn University \\ Phayathai Rd., Pathumwan, Bangkok, Thailand, 10330 \\ pimchanok.m@student.chula.ac.th*, rachata.ma@student.chula.ac.th**, and pasu.k@chula.ac.th***
}

\begin{abstract}
In this paper, we study the performance limitation of the 10-Gbps-per-channel-based coarse wavelength division multiplexed passive optical network (CWDM-PON). The computer simulation results, which are in a good agreement with the theoretical calculation results, show that the transmission of all 16 CWDM channels $(1,271-1,571 \mathrm{~nm})$ is successfully obtained at the maximum reach of $68.2 \mathrm{~km}$ under FEC limit $\left(B E R=10^{-4}\right)$. Both fiber attenuation and fiber dispersion are the main factors that limit the achievable reaches for different channel wavelengths. The power budget, which is useful for the design of the 16×10-Gbps-based CWDM-PON, is found to be $38.65 \mathrm{~dB}$.
\end{abstract}

Keywords - fiber access network, passive optical network, coarse wavelength division multiplexing, fiber attenuation, fiber dispersion.

\section{INTRODUCTION}

Nowadays, the data bandwidth consumption is increasing rapidly owing to the growth of broadband services such as IP3D-HDTV and HD video conference. Fiber-to-the-x (FTTx) based on passive optical network (PON) technology can provide sufficient data rate for those services with the reduction in operation costs. Currently, most of PON technologies available in telecommunication market are utilizing the time-division multiplexed (TDM) scheme, in which the total data rate per PON is shared among subscribers using the dynamic bandwidth allocation (DBA). The incumbent TDM-PON is currently evolving to provide the data rate of $10-\mathrm{Gbps}$ for both uplink and downlink according to 10GE-PON and 10-Gigabit-capable PON (XG-PON), standardized by IEEE and ITU-T, respectively [1], [2].

However, to support the ever-increasing bandwidth demand such as for services of the ultra-high-definition video stream ( $4 \mathrm{~K}$ and $8 \mathrm{~K}$ ), which will be certainly available in a very near future, the data rate class of 10-Gbps-per-subscriber without time sharing becomes necessary. For this case, coarse wavelength-division multiplexed (CWDM)-PON is one of the attractive solutions to resolve the bandwidth limitation of existing PON technologies [3]. However, there is still no any common standard which has been established for such CWDM-PON

In previous work [4], only 4 CWDM wavelengths with the data rate per wavelength less than $10 \mathrm{Gbps}$ has been studied. In this paper, we study the performance limitation of CWDMPON based on the data rate of $10-$ Gbps per subscriber using both computer simulation and theoretical calculation. In case that the total data rate is $160 \mathrm{Gbps}(16 \times 10 \mathrm{Gbps})$. Our result shows the maximum reach of $68.2 \mathrm{~km}$, and the power budget is found to be $38.65 \mathrm{~dB}$.

\section{CWDM-PON SYSTEM CONCEPT}

Coarse wavelength division multiplexing (CWDM), defined in ITU-T G.694.2, is a low cost WDM technology in which the usable wavelengths are assigned within the range $1,271 \mathrm{~nm}$ to $1,611 \mathrm{~nm}$ with the grid $20 \mathrm{~nm}$ [5]. In this paper, we use the CWDM wavelengths over the WDM-PON: therefore; we can specify this type of WDM-PON as the CWDM-PON.

Figure 1 shows the configuration of CWDM-PON, which consists of optical line terminal (OLT), 16 optical network units (ONUs), 2 arrayed waveguide gratings (AWGs), and single-mode fiber (SMF) ITU-T G.652.D [6]. Assuming that the OLT has full $16 \mathrm{CWDM}$ wavelengths with the data rate of 10 Gbps per wavelength, it is capable for delivering the total data rate $160 \mathrm{Gbps}$ per PON. One AWG acts as a multiplexer at OLT site, while the other AWG works as a passive wavelength splitter for delivering different CWDM wavelengths to different ONUs locating at subscriber end points. 


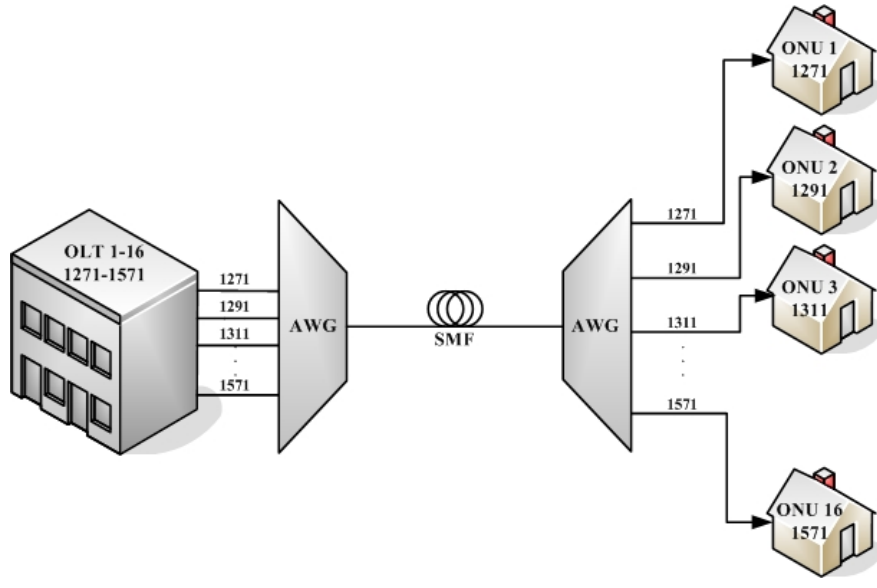

Figure 1. Configuration of CWDM-PON

\section{III.PERFormanCE ANALYSES}

\section{A. Theoretical Calculation}

TABLE 1. ChARACTERISTIC PARAMETERS OF CDWM-PON

\begin{tabular}{|c|c|c|c|c|}
\hline Items & Applications & $\begin{array}{c}\text { Max. } \\
\text { values }\end{array}$ & Units & Ref. \\
\hline $\begin{array}{l}\text { SMF's } \\
\text { attenuation } \\
\text { coefficient }\end{array}$ & $\begin{array}{l}1271 \mathrm{~nm} \\
1291 \mathrm{~nm} \\
1311 \mathrm{~nm} \\
1331 \mathrm{~nm} \\
1351 \mathrm{~nm} \\
1371 \mathrm{~nm} \\
1391 \mathrm{~nm} \\
1411 \mathrm{~nm} \\
1431 \mathrm{~nm} \\
1451 \mathrm{~nm} \\
1471 \mathrm{~nm} \\
1491 \mathrm{~nm} \\
1511 \mathrm{~nm} \\
1531 \mathrm{~nm} \\
1551 \mathrm{~nm} \\
1571 \mathrm{~nm} \\
\end{array}$ & $\begin{array}{l}0.385 \\
0.370 \\
0.350 \\
0.340 \\
0.320 \\
0.300 \\
0.320 \\
0.275 \\
0.243 \\
0.225 \\
0.213 \\
0.203 \\
0.196 \\
0.191 \\
0.190 \\
0.192 \\
\end{array}$ & $\mathrm{~dB} / \mathrm{km}$ & [6] \\
\hline Connector loss & SMF & 0.5 & $\mathrm{~dB}$ & [7] \\
\hline Splice loss & SMF & 0.1 & $\mathrm{~dB}$ & {$[8]$} \\
\hline $\begin{array}{l}\text { AWG } \\
\text { insertion loss }\end{array}$ & 16-ch CWDM & 4.0 & $\mathrm{~dB}$ & [9] \\
\hline $\begin{array}{l}\text { SMF's } \\
\text { dispersion } \\
\text { coefficient }\end{array}$ & $\begin{array}{l}1271 \mathrm{~nm} \\
1291 \mathrm{~nm} \\
1311 \mathrm{~nm} \\
1331 \mathrm{~nm} \\
1351 \mathrm{~nm} \\
1371 \mathrm{~nm} \\
1391 \mathrm{~nm} \\
1411 \mathrm{~nm} \\
1431 \mathrm{~nm} \\
1451 \mathrm{~nm} \\
1471 \mathrm{~nm} \\
1491 \mathrm{~nm} \\
1511 \mathrm{~nm} \\
1531 \mathrm{~nm} \\
1551 \mathrm{~nm} \\
1571 \mathrm{~nm}\end{array}$ & $\begin{array}{c}-4.300 \\
-2.100 \\
-0.093 \\
1.730 \\
3.473 \\
5.143 \\
6.744 \\
8.283 \\
9.761 \\
11.185 \\
12.557 \\
13.882 \\
15.161 \\
16.399 \\
17.597 \\
18.758\end{array}$ & $\mathrm{ps} / \mathrm{km} / \mathrm{nm}$ & {$[6]$} \\
\hline
\end{tabular}

The power budgets of the CWDM-PON from OLT (Tx) and to $\mathrm{ONU}(\mathrm{Rx})$ is given by

$$
P_{T}=P_{T x}-P_{R x}=\sum l_{c}+\sum l_{s}+\sum l_{A W G}+\alpha L+G_{m a r g i n},
$$

where $P_{T}$ is the power budget, $P_{T x}$ is the transmit power, $P_{R x}$ is the receiver sensitivity, $l_{c}$ is the connector loss, $l_{s}$ is the splice loss, $l_{A W G}$ is the AWG insertion loss, $\alpha$ is the attenuation coefficient, $L$ is the fiber length and $G_{m a r g i n}$ is the power margin. All are in $\mathrm{dB}$ unit.

In (1), substituting $P_{T x}=10 \mathrm{dBm}, P_{R x}=-30 \mathrm{dBm}$, according to Table 1 , the total connector loss $=1 \mathrm{~dB}$, the total splice loss $=0.4 \mathrm{~dB}$, the total AWG insertion loss $=8 \mathrm{~dB}$, $G_{\text {margin }}=3 \mathrm{~dB}$, and $\alpha$, which is dependent of CWDM wavelengths, we can estimate the maximum reach limited by fiber attenuation.

Moreover, since the accumulated dispersion tolerance for the data rate of $10 \mathrm{Gbps}$ is $1,600 \mathrm{ps} / \mathrm{nm}$ [10], we can also calculate the maximum reach of each wavelength limited by fiber dispersion. Both maximum reaches determined by the fiber attenuation and the fiber dispersion are shown in Table 2 for different CWDM wavelengths.

TABLE 2. MAXIMUM REACHES BY THEORETICAL CALCULATION

\begin{tabular}{cccc}
\hline \hline Items & Wavelengths & $\begin{array}{c}\text { Reaches limited } \\
\text { by fiber } \\
\text { attenuation } \\
{[\mathbf{k m}]}\end{array}$ & $\begin{array}{c}\text { Reaches limited } \\
\text { by fiber } \\
\text { dispersion } \\
\text { [km] }\end{array}$ \\
\hline & $1271 \mathrm{~nm}$ & 71.69 & 372.10 \\
$1291 \mathrm{~nm}$ & 74.59 & 761.90 \\
& $1311 \mathrm{~nm}$ & 78.86 & 17183.98 \\
PON & $1331 \mathrm{~nm}$ & 81.18 & 925.11 \\
reach & $1351 \mathrm{~nm}$ & 86.25 & 460.70 \\
& $1371 \mathrm{~nm}$ & 92.00 & 311.11 \\
& $1391 \mathrm{~nm}$ & 86.25 & 237.23 \\
& $1411 \mathrm{~nm}$ & 100.36 & 193.18 \\
& $1431 \mathrm{~nm}$ & 113.58 & 163.91 \\
$1451 \mathrm{~nm}$ & 122.45 & 143.04 \\
& $1471 \mathrm{~nm}$ & 129.76 & 127.41 \\
$1491 \mathrm{~nm}$ & 136.03 & 115.26 \\
& $1511 \mathrm{~nm}$ & 141.10 & 105.53 \\
& $1531 \mathrm{~nm}$ & 144.65 & 97.57 \\
& $1551 \mathrm{~nm}$ & 145.88 & 90.93 \\
& $1571 \mathrm{~nm}$ & 144.13 & 85.30 \\
\hline
\end{tabular}

\section{B. Computer Simulation}

We perform the computer simulation based on configuration of CWDM-PON shown in Figure 2 by using OptiSystem software. 


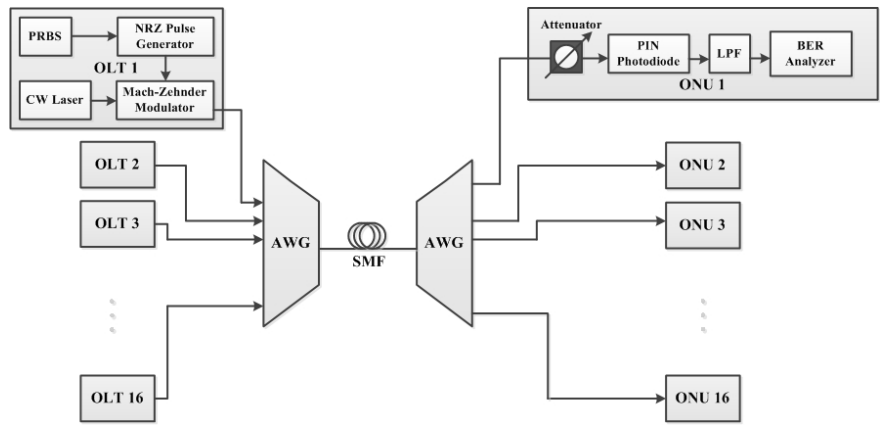

Figure 2. System configuration of CWDM-PON System

16 CWDM optical carriers are generated by using an array of CWDM continuous-wave (CW) laser. Each CW laser is modulated to exhibit the non-return-to-zero on-off keying (NRZ-OOK) shape by a Mach-Zehnder modulator with the signal power of $10 \mathrm{dBm}$ and the data rate of 10 -Gbps-perchannel, respectively. Then, all modulated signals are multiplexed by AWG and launched into a fiber. Then, the second AWG, installed outside plant, is a passive wavelength splitter for delivering different CWDM wavelengths to different ONUs. At each ONU, the optical signal is detected follow by a $7.5 \mathrm{GHz}$ low-pass filter (LPF) which exhibits Bessel Shape. Finally, we calculate the numerical BER of the detected signal at maximum eye opening [11].

\section{IV.RESULT AND DISCUSSION}

Figure 3 depicts the relation between maximum reach and numerical BER, for all $16 \mathrm{CWDM}$ channels ranged from $1,271 \mathrm{~nm}$ to $1,571 \mathrm{~nm}$. The achievable reaches for different CWDM wavelengths are determined at BER $=10^{-4}$ (with FEC). As obtained from figure 3, the maximum reach for CWDM-PON operated with full $16 \mathrm{CWDM}$ wavelength is $68.2 \mathrm{~km}$ obtained at the wavelength of $1,271 \mathrm{~nm}$.

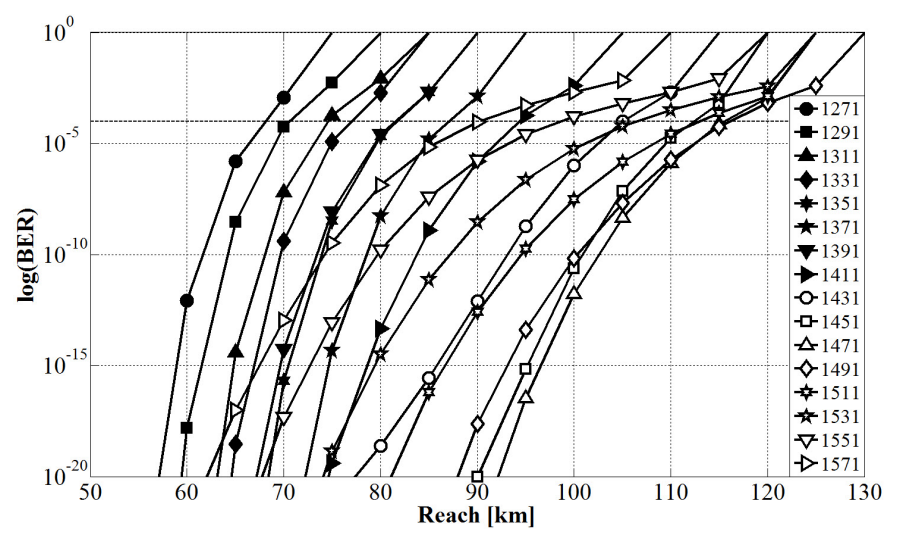

Figure 3. Relation between maximum reach and numerical BER, for all 16 CWDM wavelengths.
The maximum reach, as a function of CWDM wavelength, for the results obtained by computer simulation comparing with those shown in Table 2 is illustrated in Figure 4. Since the fiber attenuation at the wavelength range of 1,271-1,471 $\mathrm{nm}$ is higher than the attenuation at 1,491-1,571 nm, it is clearly seen that the fiber attenuation becomes the main factor that limits the achievable distance of the CWDM-PON system, rather than the fiber dispersion, which is higher at the wavelength range of 1,491-1,571 $\mathrm{nm}$ than the dispersion at $1,271-1,471 \mathrm{~nm}$. Since the fiber dispersion increases with the wavelength, at $1,491-1,571 \mathrm{~nm}$, where the fiber attenuation is relatively low, we obtain longer reach for the signal at 1,491 $\mathrm{nm}$, comparing with the reach obtained from the signal at $1,571 \mathrm{~nm}$. However, for this case when all $16 \mathrm{CWDM}$ wavelengths are fully used, the CWDM-PON system must support the transmission of all 16 wavelengths to all subscribers. Therefore, the maximum reach of the CWDMPON using all 16 wavelengths are limited by the fiber attenuation at $1,271 \mathrm{~nm}$, and is found to be $68.2 \mathrm{~km}$ with FEC $\left(\mathrm{BER}=10^{-4}\right)$. The simulation results, shown in Fig. 4 , are in a good agreement with the calculation results, shown in Table 2.

The maximum reach of $68.2 \mathrm{~km}$, obtained from simulation, can be utilized to estimate the power budget by substituting $L$ $=68.2 \mathrm{~km}$ back to Eq. (1). Then, the power budget is found to be $38.65 \mathrm{~dB}$. It should be noted that this power budget is a simplified parameter used for the design of CWDM-PON based on link budget calculation.

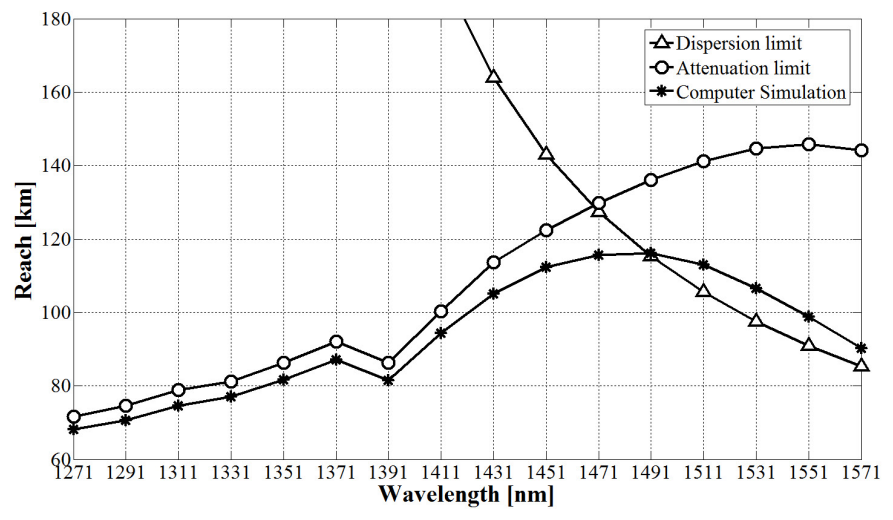

Figure 4. Comparison of maximum reaches obtained by theoretical calculation and computer simulation.

\section{Conclusions}

In this paper, we have studied the performance limitation of 10-Gbps-per-channel-based CWDM-PON. Both results obtained from theoretical calculation and computer simulation indicated that the fiber attenuation and the fiber dispersion are the dominant factors that limit the maximum reaches at the wavelength range of 1,271-1,471 nm, and 1,491-1,571 nm, respectively. For CWDM-PON which operates with all 16 CWDM wavelengths, the maximum reach was found to be 
$68.2 \mathrm{~km}$. This limitation is caused by fiber attenuation at $1,271 \mathrm{~nm}$. Finally, the power budget used for the design of CWDM-PON was estimated to be $38.65 \mathrm{~dB}$.

\section{REFERENCES}

[1] IEEE Standard for Information Technology-Telecommunications and Information Exchange Between Systems-Local and Metropolitan Area Networks-Specific Requirements Part 3: Carrier Sense Multiple Access With Collision Detection (CSMA/CD) Access Method and Physical Layer Specifications Amendment 1: Physical Layer Specifications and Management Parameters for $10 \mathrm{~Gb} / \mathrm{s}$ Passive Optical Networks, IEEE Standard 802.3av, Oct. 2009.

[2] 10-Gigabit-capable passive optical network (XG-PON) systems: Definitions, abbreviations and acronyms, ITU-T Recommendation G.987, Jun. 2012

[3] F. Effenberger, K. McCammon, and V. O'Byrne, "Passive optical network deployment in North America[Invited]," J.Opt. Netw, vol. 6, pp. 808-818, July. 2007.

[4] K. Khairi, Z. Abdul Manaf, M.S. Salleh, Z. Hamzah and R.Mohamad, "CWDM PON System: Next Generation PON for Access Network," in Proc. MICC'09, 2009, p. 765-768.

[5] Spectral grids for WDM applications: CWDM wavelength grid, ITU-T Recommendation G.694.2, Dec. 2003.

[6] Characteristics of a single-mode optical fibre and cable, ITU-T Recommendation G.652.D, Nov. 2009.

[7] Application Engineering Note: Considerations for Optical Fiber Termination 2008, Corning Cable Systems.

[8] White Paper: Setting Splice Specifications for Single-Mode Fiber Cables 2001, Corning Cable Systems.

[9] Datasheet: CWDM Optical Modules [Online]. Available: http://www.huihongfiber.com/16-channel-cwdm-mux-demuxmodule.html, Huihong Technologies, Ltd.
[10] Optical interfaces for equipments and systems relating to the synchronous digital, ITU-T Recommendation G.957, Mar. 2006.

[11] Peter J. Winzer, Rene'-Jean Essiambre, “Advanced Optical Modulation Formats," in proceedings of the IEEE, vol. 95, issue 5, pp. 952 - 985, May. 2006.

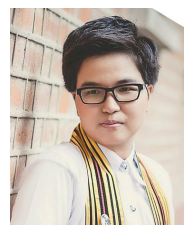

Pimchanok Montha received B.E degree from microwave and lightwave communication laboratory (MLC) department of electrical engineering, faculty of engineering, Chulalongkorn University, Thailand in 2012. She is studying the M.E. degree in electrical engineering from Chulalongkorn University. Her research about optical fiber optical, passive optical network technologies.

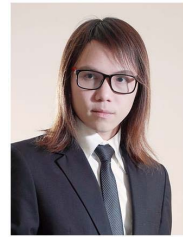

Rachata Maneekut received B.E and M.E degrees from microwave and lightwave communication laboratory (MLC), department of electrical engineering, faculty of engineering, Chulalongkorn University, Thailand in 2007 and 2010 , respectively. He is currently puesuing the $\mathrm{Ph} . \mathrm{D}$ in electrical engineering from Chulalongkorn University. His research interests are including optical fiber communication, passive optical network technologies using advance modulation scheme and optical code division multiplexing

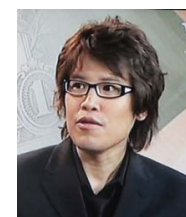

Pasu Kaewplung is an assistant professor at the department of electrical engineering, faculty of engineering, Chulalongkorn University, Thailand. He received the B.S. and M.S. degrees in electrical engineering from Yokohama National University, Yokohama, Japan, in 1996 and 1998, and Ph.D. in electrical engineering from Chulalongkorn University, Thailand. His research activities have been devoted to long-distance largecapacity optical fiber transmission systems, dispersion compensations, and the applications of nonlinear optical effects. 